\title{
Evidence of Early Vasogenic Edema Following Minor Head Injury That Can Be Reduced With a Vasopressin V1a Receptor Antagonist
}

\section{Praveen Kulkarni}

Center for Translational Neuroimaging, Northeastern Univ, Boston, MA United States

Mansi R Bhosle

Center for Translational Neuroimaging, Northeastern Univ, Boston, MA United States

Shi-fang Lu

Dept.of Biological Sciences, Lehigh University, Bethlehem, PA, United States

\section{Sade Iriah}

Center for Translational Neuroimaging, Northeastern Univ, Boston, MA United States

Neal G. Simon

Dept.of Biological Sciences, Lehigh University, Bethlehem, PA, United States

Craig Ferris ( $\nabla$ c.ferris@northeastern.edu )

Northeastern University https://orcid.org/0000-0001-9744-5214

\section{Research}

Keywords: traumatic brain injury, diffusion weighted imaging, apparent diffusion coefficient, magnetic resonance imaging, cerebellum, vasopressin 1 a antagonist

Posted Date: June 25th, 2020

DOl: https://doi.org/10.21203/rs.3.rs-37408/v1

License: (c) (i) This work is licensed under a Creative Commons Attribution 4.0 International License. Read Full License 


\section{Abstract}

Background. Does minor head injury without signs of structural brain damage cause short-term changes in vasogenic edema as measured by an increased apparent diffusion coefficient (ADC) using diffusion weighted imaging? If so, could the increase in vasogenic edema be treated with a vasopressin V1a receptor antagonist? We hypothesized that SRX251, a highly selective V1a antagonist, would reduce vasogenic edema in response to a single minor head injury.

Methods. Lightly anesthetized male rats were subjected to a sham procedure or a single hit to the forehead using a closed skull, momentum exchange model. Animals recovered in five min and were injected with saline vehicle $(n=8)$ or SRX251 $(n=8)$ at 15 min post head injury and again 7-8 hrs later. At 2 hrs, $6 \mathrm{hrs}$, and $24 \mathrm{hrs}$ post injury, rats were anesthetized and scanned for increases in ADC, a neurological measure of vasogenic edema. Sham rats $(n=6)$ were exposed to anesthesia and scannedat all time points but were not hit or treated. Images were registered to and analyzed using a 3D MRI rat atlas providing site-specific data on 150 different brain areas. These brain areas were divided into 11 major brain regions.

Results. Untreated rats with head injury showed a significant increase in global brain vasogenic edema as compared to sham and SRX251 treated rats. Edema peaked at 6 hrs in injured, untreated rats in three brain regions where changes in ADC were observed, but returned to sham levels by $24 \mathrm{hrs}$. There were regional variations in the time course of vasogenic edema and drug efficacy. Edema was significantly reduced in cerebellum and thalamus with SRX251 treatment while the basal ganglia did not show a significant response to treatment.

Conclusion: A single minor impact to the forehead causes regional increases in vasogenic edema that peak at $6 \mathrm{hrs}$ but return to baseline within a day in a subset of brain regions. Treatment with a selective $\mathrm{V} 1 \mathrm{a}$ receptor antagonist can reduce much of the edema.

\section{Background}

Traumatic brain injury (TBI) affects more than 50 million people each year worldwide across all demographic and socioeconomic groups [1]. In the United States and Europe, TBI accounts for over 4 million emergency hospital visits annually [1-3]. Major traumatic brain injuriesare a contributing factor to a third of injury-related deaths in the United States and are one of the leading causes of death and disability in persons under 35 and over 65 [2]. In the United States alone, the annual economic burden of TBI is conservatively estimated at $\$ 86$ billion [1]. While these statistics point to the significance of TBI as a health issue, one form of head injury, the effects of a single, minorimpact that doesnot require hospitalization or necessitate immediate medical attention, are not well understood[4]. The health community lists guidelines for diagnosing these"mild" head injuries that include self-reports of transient confusion, disorientation, impaired consciousness, or dysfunction in memory around the time of the 
injury and, importantly, no apparent structural damage as determined with imaging [4-6]. Despite these recognized symptoms, interventions other than rest with self-monitoring are rarely undertaken.

There areneurological complications following any closed head injury, including mild TBI[7, 8]. Edema is among the most significant complications because it is a critical component in the pathophysiology of brain injury and occurs in stages. Vasogenic edema is caused by disruption of the blood-brain barrier (BBB) and, in moderate and severe TBI, is followed by cytogenic edema from cellular swelling and lastly, by a combination of both[9]. The timing and severity of each is dependent upon the level of brain injury.The extent of edema occurring after TBI can be determined by measures of apparent diffusion coefficient (ADC) using diffusion weighted imaging (DWI)[8]. ADC is a quantitative measure of water mobility. Vasogenic edema, characterized by higher $A D C$ values, results from a change in permeability across the BBB, with an influx of water and solute into the interstitial space contributing to the extracellular volume. This increase in brain water contributes to parenchymal swelling and increase in intracranial pressure. Cellular swelling due to loss of homeostatic regulation of osmolarity across the plasma membrane results in lower ADC values.

There are currently no approved pharmaceutical treatments that can prevent, minimize, or reverse brain edema following any level of brain damage[10, 11].Several labs have studied the role of the neuropeptide arginine vasopressin (AVP) in intracranial water regulation[12-16]. AVP is a naturally occurring neuropeptide hormone involved in brain water permeability and vasoconstriction $[17,18]$. The AVP V1a (V1a) receptor subtype is highly expressed in cortical and subcortical brain areas across all mammals $[19,20]$ and AVP signaling through this receptor is strongly tied to the pathology of cerebral edema in TBI. For instance, V1a receptor density increases following TBI and infusion of V1a antagonists block increased intracranial pressure after head injury or brain lesion in animal models [21-23]. Knockout mice lacking V1a receptors show reduced edema, secondary injuries, and behavioral impairments in the days following brain damage[24]. We recently showed that systemic treatment with a highly selective V1a receptor antagonist for 5 days starting within 24 hrs of moderate/severe brain TBI significantly reduced edema and prevented cognitive deficits [25].

The present study was designed to address two questions: 1) Does minor head injury without signs of structural brain damage cause short-term changes in vasogenic edema as measured by an increase in ADC and,if so, 2) could these changes be mitigated by treatment with an AVP receptor V1a antagonist.

\section{Methods}

Animals

Male Sprague Dawley rats ( $\mathrm{n}=22)$ weighing between 300 and 325gm were obtained from Charles River Laboratories (Wilmington,Massachusetts, USA). Rats were housed in Optirat ${ }^{\circledR}$ Genll (Animal Care Systems, Inc., Centennial, CO) cages with Bed-o'Cobs ${ }^{\circledR}$ corn-cob bedding (Anderson lab bedding, Delphi, IN) mixed with Envirodri ${ }^{\mathrm{TM}}$ shredded paper (Shepards Specialty Papers, Richland, MI). The vivarium was maintained atan ambient temperature of $\left(22-24^{\circ} \mathrm{C}\right)$,humidity $(35-45 \%)$ on a $12: 12$ light:dark cycle (lights 
on at 07:00 a.m.). Rats were allowed access to food and fresh water ad libitum. Rats were imaged during the light phase of the circadian cycle. All rats were acquired and cared for in accordance with the NIH Guide for the Care and Use of Laboratory Animals. All methods and procedures described below were preapproved by the Northeastern University Institutional Animal Care and Use Committee.

\section{Treatment}

Lightly anesthetized rats were subjected to a sham procedure or a single mild hit at $7 \mathrm{~m} / \mathrm{sec}$ to the forehead, midline and rostral to Bregma, using a closed skull, momentum exchange model [26]. Originally developed by Viano and colleagues to reliably inflict mild, medium, or severe rat head injury [27], this same model was further refined by Mychasiuket al., and used to test the behavioral effects of TBI controlling for the axis of injury, rotational force, and head acceleration in different directions[28]. Animals were awake and moving in 5 min and were injected with saline vehicle $(n=8)$ or SRX251 $(n=8)$ at 15 min post head injury and again 7-8 hrs later. At 2 hrs, 6 hrs, and 24 hrs post head injury, rats were anesthetized and scanned for structural brain damage and increases in ADC, a neurological measure of vasogenic edema. Sham rats $(n=6)$ were exposed to anesthesia and scanned at all time points, but were not hit or treated. Scanning sessions lasted about $70 \mathrm{~min}$, after which animals were returned to their respective home cage.There was no evidence of structural brain damage in the 16 rats exposed to a single mild head injury during the $24 \mathrm{hr}$ study period(Supplementary Data Fig S1)

\section{Neuroimaging}

Imaging sessions were conducted using a Bruker Biospec 7.0 T/20-cm USR horizontal magnet (Bruker, Billerica, MA, USA) and a $20-\mathrm{G} / \mathrm{cmmagnetic}$ field gradient insert $(\mathrm{ID}=12 \mathrm{~cm})$ capable of a $120-\mu \mathrm{s}$ risetime. Radio frequency signals were sent and received with a quadraturevolume coil built into the animal restrainer (Animal Imaging Research,Holden, Massachusetts). The design of the restraining system included apadded head support obviating the need for ear bars, helping to reduce discomfort while minimizing motion artifact. All ratswere imaged under $1-2 \%$ isoflurane whilekeeping a respiratory rate of 40-50 breathes/min. At the beginning of eachimaging session, a high-resolution anatomical data set was collected for assessment of structural damage using the RARE pulse sequence with followingparameters, 35 slice of $0.7 \mathrm{~mm}$ thickness; field of view [FOV] $3 \mathrm{~cm} ; 256 \times 256$; repetition time [TR] 3900 msec; effective echo time [TE]48 msec; NEX 3; 6 min $14 \mathrm{sec}$ acquisition time.

\section{Diffusion Weighted Imaging - Quantitative Anisotropy}

DWI was acquired with a spin-echo echo-planar-imaging (EPI) pulse sequence having the following parameters: TR/TE $=500 / 20 \mathrm{msec}$, eight EPI segments, and 10 non-collinear gradient directions with a single b-value shell at $1000 \mathrm{~s} / \mathrm{mm} 2$ and one image with a B-value of $0 \mathrm{~s} / \mathrm{mm} 2$ (referred to as B 0). Geometrical parameters were: 48 coronal slices, each $0.313 \mathrm{~mm}$ thick (brain volume) and with in-plane resolution of $0.313 \times 0.313 \mathrm{~mm} 2$ (matrix size $96 \times 96$; FOV $30 \mathrm{~mm}^{3}$ ). The imaging protocol was repeated two times for signal averaging. Each DWI acquisition took $35 \mathrm{~min}$ and the entire MRI protocol including the anatomy lasted about 90 min. Image analysis included DWI analysis of the DWI-3D-EPI images to 
produce the maps of ADC. DWI analysis was completed with MATLAB andMedINRIA (1.9.0; http://wwwsop.inria.fr/asclepios/software/MedINRIA/index.php) software. Because sporadic excessive breathing during DWI acquisition can lead to significant image motion artifacts that are apparent only in the slices sampled when motion occurred, each image (for each slice and each gradient direction) was screened prior to DWI analysis. If found, acquisition points with motion artifacts were eliminated from analyses.

For statistical comparisons among rats, each brain volume was registered to a 3D MRI Rat Brain Atlas (৫) 2012 Ekam Solutions LLC, Boston, MA) allowing voxel- and region-based statistics. All image transformations and statistical analyses were carried out using the in-house MIVA software (http://ccni.wpi.edu/). For each rat, the B 0 image was co-registered with the B 0 template (using a 6parameter rigid-body transformation). The co-registration parameters were then applied on the DWI ADC maps. Normalization was performed on the maps because they provided the most detailed visualization of brain structures and allowed for more accurate normalization. The normalization parameters were then smoothed with a $0.3-\mathrm{mm}$ Gaussian kernel. To ensure that $A D C$ values werenot affected significantly by the pre-processing steps, the 'nearest neighbor' option was used following registration and normalization.Statistical differences in measures of DWI between experimental groups were determined using two-way ANOVA followed by Bonferroni post hoc tests (alpha set at 5\%).

The 3D MRI rat atlas has 173 segmented, annotated brain areas. For this study, 150areas were chosen for analysis because they could be organized into well-defined neuroanatomical regions. Areas excluded were white matter tracts because they traverse several brain regions. Circumventricular organs, e.g. anterior and posterior pituitary, pineal gland, area postrema, median eminence and small adjacent areas like the arcuate and retrochiasmatic nuclei, were also excluded because of their larger, more fenestrated blood vessels.Also excluded were areas with no clear regional organization e.g., prerubral field. The remaining 150 brain areas were divided into 11 brain regions: cerebellum (20), cortex (19), thalamus (20), basal ganglia (10), hypothalamus (14), hippocampus (9), prefrontal cortex (9), olfactory bulb/cortex (8), amygdala (8), midbrain/pons (12), brainstem (21). The areas and their average ADC values for each experimental condition and for 2, 6 and $24 \mathrm{hrs}$, is provided in Supplementary Data Excel S1. The organization was based on conventional neuroanatomy and an effort to keep individual brain areas localized and contiguous within a region. The olfactory bulb/cortex is the exception as the piriform cortex extends some distance caudally along the ventral lateral cortex away from the bulbs.

\section{Results}

Shown in Fig 1 are box and whisker scatter plots for measures of ADC in the whole brain (150 areas combined) for each experimental condition over the three time points following head injury. The horizontal line in each box denotes the median. The two-way ANOVA shows a significant main effect among treatments, time of measurement over the $24 \mathrm{hr}$ period, and interaction between both. At $2 \mathrm{hrs}$ post head injury, vehicle treated rats (blue box) showed a significant $(p<0.001)$ increase over sham (black box) and SRX251 (red box). ADC values in injured vehicle-treatedanimals were still significantly greater 
than sham or SRX251 $(\mathrm{p}<0.05)$ at $6 \mathrm{hr}$. At the $24 \mathrm{hr}$ time point, there were no significant differences among the groups in $A D C$ values.

To determine which areas of the brain were most sensitive to this single mild head impact directed to the forebrain, ANOVA's with post hoc analyses were run on the 11 brain regions. Only the cerebellum, thalamus, and basal ganglia showed a significant increase in ADC between experimental groups. Fig 2 shows scatter plots for ADC measures in the cerebellum. The two-way ANOVA results and list of twenty brain areas that comprise the cerebellum taken from the rat 3D MRI atlas are shown. At 2 and 6 hrs post impact, injured vehicle-treated rats present with significantly greater edema than sham $(p<0.01)$, a difference that was no longer found at $24 \mathrm{hrs}$. At $6 \mathrm{hrs}$, ADC values peak in injured vehicle animals and significantly exceed the two hr levels $(p<0.02)$. SRX251 treatment significantly reduced edema at the 2 and $24 \mathrm{hr}$ time points compared to vehicle ( $p<0.001)$, but the effect was not significant at the $6 \mathrm{hr}$ time point. There are no significant differences at any time point between SRX251 and sham rats.

Fig 3 shows scatter plots for ADC measures in the thalamus, the two-way ANOVA table and a list of twenty brain areas that comprise the thalamus taken from the rat 3D MRI atlas. The profile of ADC values over the $24 \mathrm{hr}$ period for each of the experimental conditions are similar to the cerebellum. At 2 and 6 hrs post impact, injured vehicle-treated rats showed significantly greater edema than sham (both p's<0.001). Edema in the vehicle group peaked at $6 \mathrm{hrs}$ and is significantly greater than both sham and SRX251 ( $<<0.001)$. The SRX251 treatment significantly reduced edema compared to vehicle at 2 and 6 hrs $(p<0.001)$ and $24 \mathrm{~h}(p<0.01)$.There are no significant differences at any time point between SRX251 and sham rats.

Fig 4 shows scatter plots for ADC measures in the basal ganglia, the two-way ANOVA table, and a list of ten brain areas that comprise the basal ganglia taken from the rat 3D MRI atlas. The change in $A D C$ measures at $2 \mathrm{hr}$ is not significantly different among conditions. By 6 hrs,injured vehicle-treated rats show significantly greater edema than sham but not SRX251. At $24 \mathrm{hrs}, A D C$ values show no significant differences between conditions. At no time point is SRX251 significantly different from sham.

The 3D reconstruction shown in Fig $\mathbf{5}$ summarizes the brain regions with significant increases in edema over the $24 \mathrm{hr}$ period following impact to the forebrain (location depicted in black). The thalamus (light red) and cerebellum (dark red) were responsive to SRX251 treated and we found significantly reduced edema in these areas. While the basal ganglia only showed an increase in edema at $6 \mathrm{hrs}$, as noted above, a decrease in ADC was present in response to SRX2521 but did not differ significantly when compared to vehicle (area in blue).

\section{Discussion}

This was an initial study testing the effects of a single, minor head impact on the development of early edema in a closed head, momentum exchange model of brain injury and the ability of a V1a receptor antagonist to reduce or block observed changes. The ADC from diffusion weighted imaging was used as a proxy for vasogenic edema. In this model of mild head injury, edema was significantly increased in 
whole brain and a subset of the 11 regions that were tested, including basal ganglia, cerebellum, and thalamus, without evidence of structural damage. The observed edema was transient because at 24 hours post-injury, vehicle-treated rats with mild head injury did not differ from sham controls in ADC. V1a antagonist treatment significantly reduced edema compared to vehicle treatment in whole brain, thalamus, and cerebellum.

Edema is a critical component in the pathophysiology of TBI and can occur within the first few hrs postinjury[29-31]. The type ofedema occurring after TBI can be determined using DWI with ADC, a quantitative measure of water mobility[29, 32-34].Vasogenic edema, characterized by higher ADC values, contributes to parenchymal swelling and an increase in intracranial pressure. In the present study, only higher ADC values were found in the affected regions, indicating that a single, mild head injury can induce vasogenic edema.

An important question is why the cerebellum and thalamus, regions caudal to the site of impact on the forehead, but not the prefrontal cortex immediately beneath the site of impact, show the greatest increases in ADC. The transmission of mechanical force down white matter tracts and along brain areas abutting the ventricular system may offer an explanation [35]. The cerebellum is recognized as beingparticularly vulnerable to mild TBI [36-39] andneuroradiological evidence of cerebellar dysfunction has beenadvanced as a diagnostic biomarker of TBI [39]. Because this is the only studywe knowof that used a closed-head, mild injury protocol, we cannot readily compare our findings to other rodent models that producestructural brain damage.

The increase in $A D C$, which reflects vasogenic edema, suggests a change in the permeability of the BBB with a single mild head impact. BBB permeability increases within 1-4 hr hrs after brain damage in rodent models of TBI based on extravasation of blood biomarkers, e.g. Evan blue, plasma immunoglobulins, horse radish peroxidase, and albumin[40-43]. Similar results, albeit in moderate TBI models, have been reported in rats usingdynamic contrast enhanced (DCE) MRI to measure BBB permeability $[44,45]$ and in humans, DCE MRI shows increased BBB permeability around damaged tissue within 24 hrs of injury that persists for days [46].Athletes playing American football and thought to have mild,sub-concussive head injuries show evidence of increased BBB permeability with DCE MRI[47]. Using DCE-MRI, O'Keeffe and colleagues reported BBB disruption in response to repetitive mild concussions in rugby players after a season and mixed martial arts fighters within days after a competitive fight [48]. There were no significant differences in self-reported concussions between these players and control subjects (track and field athletes).Players with multiple subconcussive collisions in American football show elevated blood levels of astrocytic protein S100B thought to be due to BBB disruption [49]. Interestingly, professional boxers show an increase in $A D C$ values in large white matter tracts and a general increase in brain diffusivity attributed to the cumulative effect of multiple non-severe head impacts [50-52].To our knowledge, these are the first data reporting evidence of global and region-specific increases in brain edema to a single, mild head injury in the absence of structural brain damage. 
These data reinforce concerns expressed by others about the long-term effect of mild head injury [48]. For example, mild head injury begins with an impact that by itself may be recorded but not pursued as needing medical attention. Yet here we show there are global changes in vasogenic edema presumably caused by disruption in the BBB. Newsomeet al. [53]reported modest neurocognitiveabnormalities and increased functional connectivity in adolescent athletes with sports related concussions compared to age-matched, orthopedically injured controls. Despite these signs of altered cortical function, postconcussive symptoms were judged to be resolvedand athletes could return to competition. Indeed, more adolescent players are suffering from undetected neurological problems than previously thought [54]. A single season of high school American football producesDWI changes in diffusivity in the absence of clinical concussion[55]. Multiple mild head injuries are a risk factor for cognitive and emotional impairment and neurodegenerative disorders in athletes[56].

Evidence for the involvement AVP in the development of edema associated with TB is substantial. Following a moderate impact to the brain, the tissue surrounding the damage parenchyma increases the expression of V1a receptors on neurons, astrocytes and endothelium of microvessels, an effect that occurs within hrs and persists for days $[57,58]$. AVP appears to have a role in post-traumatic neuroinflammation as the proinflammatory chemokines in endothelial cells and astrocytes of damaged tissue are reduced in AVP-deficient Brattleboro rats compared to wild-type controls [59,60]. With brain damage,the water content from vasogenic edema goes up dramatically in the first 5 to $24 \mathrm{hrs}[23,30,31$. The increase in brain edema can be reduced by the continuous intravenous infusion of SR49059, a V1a receptor antagonist,beginning immediately after head injury $[22,23,30]$. The intracerebroventricular injection of V1a receptor antagonists e.g., SR-49059, V1880[61] or the peptidic deamino-Pen(1), O-Me$\operatorname{Tyr}(2), \operatorname{Arg}(8)]$-vasopressin[31, 62], are also effective but only when given within the first few hrs of injury[61].Moderate head injury is associated with elevated levels of the water channel AQP4, GFAP, and V1a receptor, and disruption in sodium/potassium balance, all of which can be corrected by continuous exposure to SR49059[22, 23, 30]. The edema in the these moderate TBI models is reduced in V1a null mice[24].In a recent study, we reported that AVN576, an orally active V1a receptor antagonist,givenipbeginning 24 hrs post injury for 5 days, could effectively reduce edema following TBI with brain damage[25].

\section{Limitations and Data Interpretation}

This was aninitial study with a limited number of animals to explore the possibility that we could measure significant changes in ADC following a single mild head impact. As such, there were several limitations: 1) The sensitivity of DWI did not allow us to examine 150 individual brain areas; instead, we were only able to observe change in ADC values in the whole brain and in three brain regions, cerebellum, thalamus, and basal ganglia;2) Would there have been sex differences if female rats also had been tested? We are aware of the many studies reporting sex differences in response to TBI, e.g. [63-68]. Recent reviews report there are male/female differences in morbidity and mortality following TBI $[69,70]$. However, the data collected over decades of preclinical and clinical research are inconsistent, certainly as it relates to the role of estrogen and progesterone[71]. Further, these initial studies were not designed to 
address the issues surrounding hormones and head injury;3) While there was no evidence of structural brain damage, post mortem histology looking at site-specific or regional signs of inflammation or alterations in BBB permeability would have helpedto interpret the findings. 4) Animals were exposed to light isoflurane anesthesia four times over a $24 \mathrm{hr}$ period. This necessary condition over this abbreviated time span for imaging precluded taking any meaningful measures of motor or cognitive behavior.

\section{Conclusion}

We were interested in two primary questions 1) could we detect global changes in brain edema using $A D C$, and 2) could these changes be mitigated by drug treatment with a vasopressin 1a antagonist?This study differs from previous animal TBI studies as it relies on imaging, without animal behavior, to evaluate the consequences of a mild head impact.The Glasgow Coma Scale of 13-15 defines a head injury as "mild" based on measures of motor behavior, verbal responses and eye opening, with loss of consciousness and short hospitalization [72]. With CT and MRI, physical damage to the brain can be confirmed, adjusting the classification to "mild with complication" [73]. Organized sports in adolescence added another dimension to the characterization of "mild." The Centers for Disease Control and Prevention, World Health Organization and the Veteran's Administration have included self-reports of transient confusion, disorientation, impaired consciousness or dysfunction in memory around the time of the injury - importantly there should be no structural damage as determined with imaging [4-6]. This study in rats used a single head impact that caused no structural damage to the brain but clearly showed global and regional increases in vasogenic edema that appear within $2 \mathrm{hrs}$, increase at $6 \mathrm{hrs}$, but return to baseline within a day. Systemic treatment with a selective V1a receptor antagonist that crosses the BBBreduced much of the vasogenic edema. These findings highlight the potential risk to a single mild head injury and the role AVP in acute vasogenic edema.

\section{List Of Abbreviations}

EPI - echo planar imaging

MRI - magnetic resonance imaging

AVP - arginine vasopressin

$\mathrm{V} 1 \mathrm{a}$ - vasopressin $\mathrm{V} 1 \mathrm{a}$ receptor

FOV - field of view

RARE - rapid acquisition relaxation enhanced

BBB - blood-brain barrier

ADC - apparent diffusion coefficient 
DWI - diffusion weighted imaging

TBI - traumatic brain injury

DCE - dynamic contrast enhanced

TR - repetition time

TE - echo time

NEX - number of excitations

\section{Declarations}

Ethics approval and consent to participate

Not applicable

Consent for publication

Yes

\section{Availability of data and material}

All data can be accessed through a link to Mandeley. DOI to follow

Competing interests. C.F.F has a financial interest in Animal Imaging Research, the company that makes the RF electronics and holders for animal imaging. C.F.F, and N.G.S., and S.L.

holdequityinAzevanPharmaceuticals,Inc.S.L. receivespaymentasan employee of Azevan and NGS is aconsultanttothe company.

\section{Funding}

1R43NS110343-01A1 Ferris

\section{Authors' contributions}

All of the authors have contributed substantially to the manuscript.

Concept, drafting and interpretation - Ferris, Simon, Kulkarni

Execution and analysis - Kulkarni,Bhosle, Iriah, Lu

\section{Acknowledgements}

none

\section{Bibliography}


1. Maas AIR, Menon DK, Adelson PD, Andelic N, Bell MJ, Belli A, Bragge P, Brazinova A, Buki A, Chesnut $\mathrm{RM}$, et al: Traumatic brain injury: integrated approaches to improve prevention, clinical care, and research.Lancet Neurol 2017, 16:987-1048.

2. Taylor CA, Bell JM, Breiding MJ, Xu L: Traumatic Brain Injury-Related Emergency Department Visits, Hospitalizations, and Deaths - United States, 2007 and 2013.MMWR Surveill Summ 2017, 66:1-16.

3. Majdan M, Plancikova D, Maas A, Polinder S, Feigin V, Theadom A, Rusnak M, Brazinova A, Haagsma $\mathrm{J}$ : Years of life lost due to traumatic brain injury in Europe: A cross-sectional analysis of 16 countries.PLoS Med 2017, 14:e1002331.

4. Cassidy JD, Carroll LJ, Peloso PM, Borg J, von Holst H, Holm L, Kraus J, Coronado VG, Injury WHOCCTFOMTB: Incidence, risk factors and prevention of mild traumatic brain injury: results of the WHO Collaborating Centre Task Force on Mild Traumatic Brain Injury.J Rehabil Med 2004:28-60.

5. T.B.I.W.G.: Management of concussion/m, VAVDoD clinical practice guideline for management of concussion/mild traumatic brain injury.J Rehabil Res Dev 2009, 46:1-68.

6. Report to Congress on Traumatic Brain Injury in the United States: Epidemiology and Rehabilitation. National Center for Injury Prevention and Control; Division of Unintentional Injury Prevention, Centers for Disease Control and Prevention, Atlanta, GA.; 2018.

7. Katz DI, Cohen SI, Alexander MP: Mild traumatic brain injury.Handb Clin Neurol 2015, 127:131-156.

8. Toth A: Magnetic Resonance Imaging Application in the Area of Mild and Acute Traumatic Brain Injury: Implications for Diagnostic Markers? In Brain Neurotrauma: Molecular, Neuropsychological, and Rehabilitation Aspects. Edited by Kobeissy FH. Boca Raton (FL); 2015: Frontiers in Neuroengineering].

9. Jha RM, Kochanek PM, Simard JM: Pathophysiology and treatment of cerebral edema in traumatic brain injury.Neuropharmacology 2019, 145:230-246.

10. Diaz-Arrastia R, Kochanek PM, Bergold P, Kenney K, Marx CE, Grimes CJ, Loh LT, Adam LT, Oskvig D, Curley KC, Salzer W: Pharmacotherapy of traumatic brain injury: state of the science and the road forward: report of the Department of Defense Neurotrauma Pharmacology Workgroup.J Neurotrauma 2014, 31:135-158.

11. Gultekin R, Huang S, Clavisi O, Pattuwage L, Konig TC, Gruen R: Pharmacological interventions in traumatic brain injury: Can we rely on systematic reviews for evidence? Injury 2016, 47:516-524.

12. Donkin JJ, Vink R: Mechanisms of cerebral edema in traumatic brain injury: therapeutic developments. Curr Opin Neurol 2010, 23:293-299.

13. Rossi-Mossuti F, Fisch U, Schoettker P, Gugliotta M, Morard M, Schucht P, Schatlo B, Levivier M, Walder B, Fandino J: Surgical Treatment of Severe Traumatic Brain Injury in Switzerland: Results from a Multicenter Study.J Neurol Surg A Cent Eur Neurosurg 2016, 77:36-45.

14. Cui T, Zhu G: Ulinastatin attenuates brain edema after traumatic brain injury in rats.Cell Biochem Biophys 2015, 71:595-600.

15. Kleindienst A, Dunbar JG, Glisson R, Marmarou A: The role of vasopressin V1A receptors in cytotoxic brain edema formation following brain injury.Acta Neurochir (Wien) 2013, 155:151-164. 
16. Amiry-Moghaddam M, Otsuka T, Hurn PD, Traystman RJ, Haug FM, Froehner SC, Adams ME, Neely JD, Agre P, Ottersen OP, Bhardwaj A: An alpha-syntrophin-dependent pool of AQP4 in astroglial endfeet confers bidirectional water flow between blood and brain.Proc Natl Acad Sci U S A 2003, 100:2106-2111.

17. Morrison TR, Melloni RH, Jr.: The role of serotonin, vasopressin, and serotonin/vasopressin interactions in aggressive behavior.Curr Top Behav Neurosci 2014, 17:189-228.

18. Kozniewska E, Romaniuk K: Vasopressin in vascular regulation and water homeostasis in the brain.J Physiol Pharmacol 2008, 59 Suppl 8:109-116.

19. Ostrowski NL, Lolait SJ, Young WS, 3rd: Cellular localization of vasopressin V1a receptor messenger ribonucleic acid in adult male rat brain, pineal, and brain vasculature.Endocrinology 1994, 135:15111528.

20. Young LJ, Toloczko D, Insel TR: Localization of vasopressin (V1a) receptor binding and mRNA in the rhesus monkey brain.J Neuroendocrino/ 1999, 11:291-297.

21. Bemana I, Nagao S: Treatment of brain edema with a nonpeptide arginine vasopressin V1 receptor antagonist OPC-21268 in rats.Neurosurgery 1999, 44:148-154; discussion 154-145.

22. Filippidis AS, Liang X, Wang W, Parveen S, Baumgarten CM, Marmarou CR: Real-time monitoring of changes in brain extracellular sodium and potassium concentrations and intracranial pressure after selective vasopressin-1a receptor inhibition following focal traumatic brain injury in rats. $J$ Neurotrauma 2014, 31:1258-1267.

23. Marmarou CR, Liang X, Abidi NH, Parveen S, Taya K, Henderson SC, Young HF, Filippidis AS, Baumgarten CM: Selective vasopressin-1a receptor antagonist prevents brain edema, reduces astrocytic cell swelling and GFAP, V1aR and AQP4 expression after focal traumatic brain injury.Brain Res 2014, 1581:89-102.

24. Rauen K, Trabold R, Brem C, Terpolilli NA, Plesnila N: Arginine vasopressin V1a receptor-deficient mice have reduced brain edema and secondary brain damage following traumatic brain injury. $J$ Neurotrauma 2013, 30:1442-1448.

25. Morrison TR, Kulkarni P, Cai X, Iriah S, Aggarwal D, Lu SF, Simon NG, Madularu D, Ferris CF: Treating head injury using a novel vasopressin 1a receptor antagonist.Neurosci Lett 2020, 714:134565.

26. Kulkarni P, Morrison TR, Cai X, Iriah S, Simon N, Sabrick J, Neuroth L, Ferris CF: Neuroradiological Changes Following Single or Repetitive Mild TBI.Front Syst Neurosci 2019, 13:34.

27. Viano DC, Hamberger A, Bolouri H, Saljo A: Concussion in professional football: animal model of brain injury-part 15.Neurosurgery 2009, 64:1162-1173; discussion 1173.

28. Mychasiuk R, Hehar H, Candy S, Ma I, Esser MJ: The direction of the acceleration and rotational forces associated with mild traumatic brain injury in rodents effect behavioural and molecular outcomes.J Neurosci Methods 2016, 257:168-178.

29. Barzo P, Marmarou A, Fatouros P, Hayasaki K, Corwin F: Contribution of vasogenic and cellular edema to traumatic brain swelling measured by diffusion-weighted imaging.J Neurosurg 1997, 87:900-907. 
30. Taya K, Gulsen S, Okuno K, Prieto R, Marmarou CR, Marmarou A: Modulation of AQP4 expression by the selective V1a receptor antagonist, SR49059, decreases trauma-induced brain edema.Acta Neurochir Supp/2008, 102:425-429.

31. Trabold R, Krieg S, Scholler K, Plesnila N: Role of vasopressin V(1a) and V2 receptors for the development of secondary brain damage after traumatic brain injury in mice.J Neurotrauma 2008, 25:1459-1465.

32. Hudak AM, Peng L, Marquez de la Plata C, Thottakara J, Moore C, Harper C, McColl R, Babcock E, Diaz-Arrastia R: Cytotoxic and vasogenic cerebral oedema in traumatic brain injury: assessment with FLAIR and DWI imaging.Brain Inj 2014, 28:1602-1609.

33. Ren $\mathrm{H}, \mathrm{Lu} \mathrm{H}$ : Dynamic features of brain edema in rat models of traumatic brain injury.Neuroreport 2019, 30:605-611.

34. Ito J, Marmarou A, Barzo P, Fatouros P, Corwin F: Characterization of edema by diffusion-weighted imaging in experimental traumatic brain injury.J Neurosurg 1996, 84:97-103.

35. Finan JD: Biomechanical simulation of traumatic brain injury in the rat.Clin Biomech (Bristol, Avon) 2019, 64:114-121.

36. Peskind ER, Petrie EC, Cross DJ, Pagulayan K, McCraw K, Hoff D, Hart K, Yu CE, Raskind MA, Cook DG, Minoshima S: Cerebrocerebellar hypometabolism associated with repetitive blast exposure mild traumatic brain injury in 12 Iraq war Veterans with persistent post-concussive symptoms. Neuroimage 2011, 54 Suppl 1:S76-82.

37. Nathan DE, Oakes TR, Yeh PH, French LM, Harper JF, Liu W, Wolfowitz RD, Wang BQ, Graner JL, Riedy $\mathrm{G}$ : Exploring variations in functional connectivity of the resting state default mode network in mild traumatic brain injury.Brain Connect 2015, 5:102-114.

38. Meabon JS, Huber BR, Cross DJ, Richards TL, Minoshima S, Pagulayan KF, Li G, Meeker KD, Kraemer $\mathrm{BC}$, Petrie EC, et al: Repetitive blast exposure in mice and combat veterans causes persistent cerebellar dysfunction.Sci Trans/ Med 2016, 8:321ra326.

39. Vergara VM, Mayer AR, Damaraju E, Kiehl KA, Calhoun V: Detection of Mild Traumatic Brain Injury by Machine Learning Classification Using Resting State Functional Network Connectivity and Fractional Anisotropy.J Neurotrauma 2017, 34:1045-1053.

40. Habgood MD, Bye N, Dziegielewska KM, Ek CJ, Lane MA, Potter A, Morganti-Kossmann C, Saunders NR: Changes in blood-brain barrier permeability to large and small molecules following traumatic brain injury in mice.Eur J Neurosci 2007, 25:231-238.

41. Baskaya MK, Rao AM, Dogan A, Donaldson D, Dempsey RJ: The biphasic opening of the blood-brain barrier in the cortex and hippocampus after traumatic brain injury in rats.Neurosci Lett 1997, 226:3336.

42. Tanno H, Nockels RP, Pitts LH, Noble LJ: Breakdown of the blood-brain barrier after fluid percussive brain injury in the rat. Part 1: Distribution and time course of protein extravasation.J Neurotrauma 1992, 9:21-32. 
43. Fukuda K, Tanno H, Okimura Y, Nakamura M, Yamaura A: The blood-brain barrier disruption to circulating proteins in the early period after fluid percussion brain injury in rats.J Neurotrauma 1995, 12:315-324.

44. Li W, Watts L, Long J, Zhou W, Shen Q, Jiang Z, Li Y, Duong TQ: Spatiotemporal changes in bloodbrain barrier permeability, cerebral blood flow, T2 and diffusion following mild traumatic brain injury.Brain Res 2016, 1646:53-61.

45. Yu M, Wang M, Yang D, Wei X, Li W: Dynamics of blood brain barrier permeability and tissue microstructure following controlled cortical impact injury in rat: A dynamic contrast-enhanced magnetic resonance imaging and diffusion kurtosis imaging study.Magn Reson Imaging 2019, 62:19.

46. Jungner M, Siemund R, Venturoli D, Reinstrup P, W SC, Bentzer P: Blood-brain barrier permeability following traumatic brain injury.Minerva Anestesio/ 2016, 82:525-533.

47. Weissberg I, Veksler R, Kamintsky L, Saar-Ashkenazy R, Milikovsky DZ, Shelef I, Friedman A: Imaging blood-brain barrier dysfunction in football players.JAMA Neuro/ 2014, 71:1453-1455.

48. O'Keeffe E, Kelly E, Liu Y, Giordano C, Wallace E, Hynes M, Tiernan S, Meagher A, Greene C, Hughes S, et al: Dynamic Blood-Brain Barrier Regulation in Mild Traumatic Brain Injury.J Neurotrauma 2020, 37:347-356.

49. Marchi N, Bazarian JJ, Puvenna V, Janigro M, Ghosh C, Zhong J, Zhu T, Blackman E, Stewart D, Ellis $\mathrm{J}$, et al: Consequences of repeated blood-brain barrier disruption in football players.PLoS One 2013, 8:e56805.

50. Chappell MH, Ulug AM, Zhang L, Heitger MH, Jordan BD, Zimmerman RD, Watts R: Distribution of microstructural damage in the brains of professional boxers: a diffusion MRI study.J Magn Reson Imaging 2006, 24:537-542.

51. Zhang L, Ravdin LD, Relkin N, Zimmerman RD, Jordan B, Lathan WE, Ulug AM: Increased diffusion in the brain of professional boxers: a preclinical sign of traumatic brain injury? AJNR Am J Neuroradiol 2003, 24:52-57.

52. Zhang L, Heier LA, Zimmerman RD, Jordan B, Ulug AM: Diffusion anisotropy changes in the brains of professional boxers.AJNR Am J Neuroradiol 2006, 27:2000-2004.

53. Newsome MR, Li X, Lin X, Wilde EA, Ott S, Biekman B, Hunter JV, Dash PK, Taylor BA, Levin HS: Functional Connectivity Is Altered in Concussed Adolescent Athletes Despite Medical Clearance to Return to Play: A Preliminary Report.Front Neurol 2016, 7:116.

54. Talavage TM, Nauman EA, Breedlove EL, Yoruk U, Dye AE, Morigaki KE, Feuer H, Leverenz LJ: Functionally-detected cognitive impairment in high school football players without clinicallydiagnosed concussion.J Neurotrauma 2014, 31:327-338.

55. Davenport EM, Whitlow CT, Urban JE, Espeland MA, Jung Y, Rosenbaum DA, Gioia GA, Powers AK, Stitzel JD, Maldjian JA: Abnormal white matter integrity related to head impact exposure in a season of high school varsity football.J Neurotrauma 2014, 31:1617-1624. 
56. Manley G, Gardner AJ, Schneider KJ, Guskiewicz KM, Bailes J, Cantu RC, Castellani RJ, Turner M, Jordan BD, Randolph C, et al: A systematic review of potential long-term effects of sport-related concussion.Br J Sports Med 2017, 51:969-977.

57. Szmydynger-Chodobska J, Chung I, Kozniewska E, Tran B, Harrington FJ, Duncan JA, Chodobski A: Increased expression of vasopressin v1a receptors after traumatic brain injury.J Neurotrauma 2004, 21:1090-1102.

58. Pascale CL, Szmydynger-Chodobska J, Sarri JE, Chodobski A: Traumatic brain injury results in a concomitant increase in neocortical expression of vasopressin and its V1a receptor.J Physiol Pharmacol 2006, 57 Suppl 11:161-167.

59. Szmydynger-Chodobska J, Fox LM, Lynch KM, Zink BJ, Chodobski A: Vasopressin amplifies the production of proinflammatory mediators in traumatic brain injury.J Neurotrauma 2010, 27:14491461.

60. Szmydynger-Chodobska J, Gandy JR, Varone A, Shan R, Chodobski A: Synergistic interactions between cytokines and AVP at the blood-CSF barrier result in increased chemokine production and augmented influx of leukocytes after brain injury.PLoS One 2013, 8:e79328.

61. Krieg SM, Trabold R, Plesnila N: Time-Dependent Effects of Arginine-Vasopressin V1 Receptor Inhibition on Secondary Brain Damage after Traumatic Brain Injury.J Neurotrauma 2017, 34:13291336.

62. Krieg SM, Sonanini S, Plesnila N, Trabold R: Effect of small molecule vasopressin V1a and V2 receptor antagonists on brain edema formation and secondary brain damage following traumatic brain injury in mice.J Neurotrauma 2015, 32:221-227.

63. Colantonio A, Harris JE, Ratcliff G, Chase S, Ellis K: Gender differences in self reported long term outcomes following moderate to severe traumatic brain injury.BMC Neuro/ 2010, 10:102.

64. Colvin AC, Mullen J, Lovell MR, West RV, Collins MW, Groh M: The role of concussion history and gender in recovery from soccer-related concussion. Am J Sports Med 2009, 37:1699-1704.

65. Covassin T, Schatz P, Swanik CB: Sex differences in neuropsychological function and postconcussion symptoms of concussed collegiate athletes.Neurosurgery 2007, 61:345-350; discussion 350-341.

66. Broshek DK, Kaushik T, Freeman JR, Erlanger D, Webbe F, Barth JT: Sex differences in outcome following sports-related concussion.J Neurosurg 2005, 102:856-863.

67. Bazarian JJ, Blyth B, Mookerjee S, He H, McDermott MP: Sex differences in outcome after mild traumatic brain injury.J Neurotrauma 2010, 27:527-539.

68. Sandel NK, Schatz P, Goldberg KB, Lazar M: Sex-Based Differences in Cognitive Deficits and Symptom Reporting Among Acutely Concussed Adolescent Lacrosse and Soccer Players.Am J Sports Med 2017, 45:937-944.

69. Mollayeva T, Mollayeva S, Colantonio A: Traumatic brain injury: sex, gender and intersecting vulnerabilities. Nat Rev Neurol 2018, 14:711-722. 
70. Caplan HW, Cox CS, Bedi SS: Do microglia play a role in sex differences in TBI? J Neurosci Res 2017, 95:509-517.

71. Wright DW, Yeatts SD, Silbergleit R: Progesterone in traumatic brain injury.N Eng/ J Med 2015, 372:1766-1767.

72. Jennett B, Teasdale G: Aspects of coma after severe head injury.Lancet 1977, 1:878-881.

73. Levin HS, Williams DH, Eisenberg HM, High WM, Jr., Guinto FC, Jr.: Serial MRI and neurobehavioural findings after mild to moderate closed head injury.J Neurol Neurosurg Psychiatry 1992, 55:255-262.

\section{Figures}

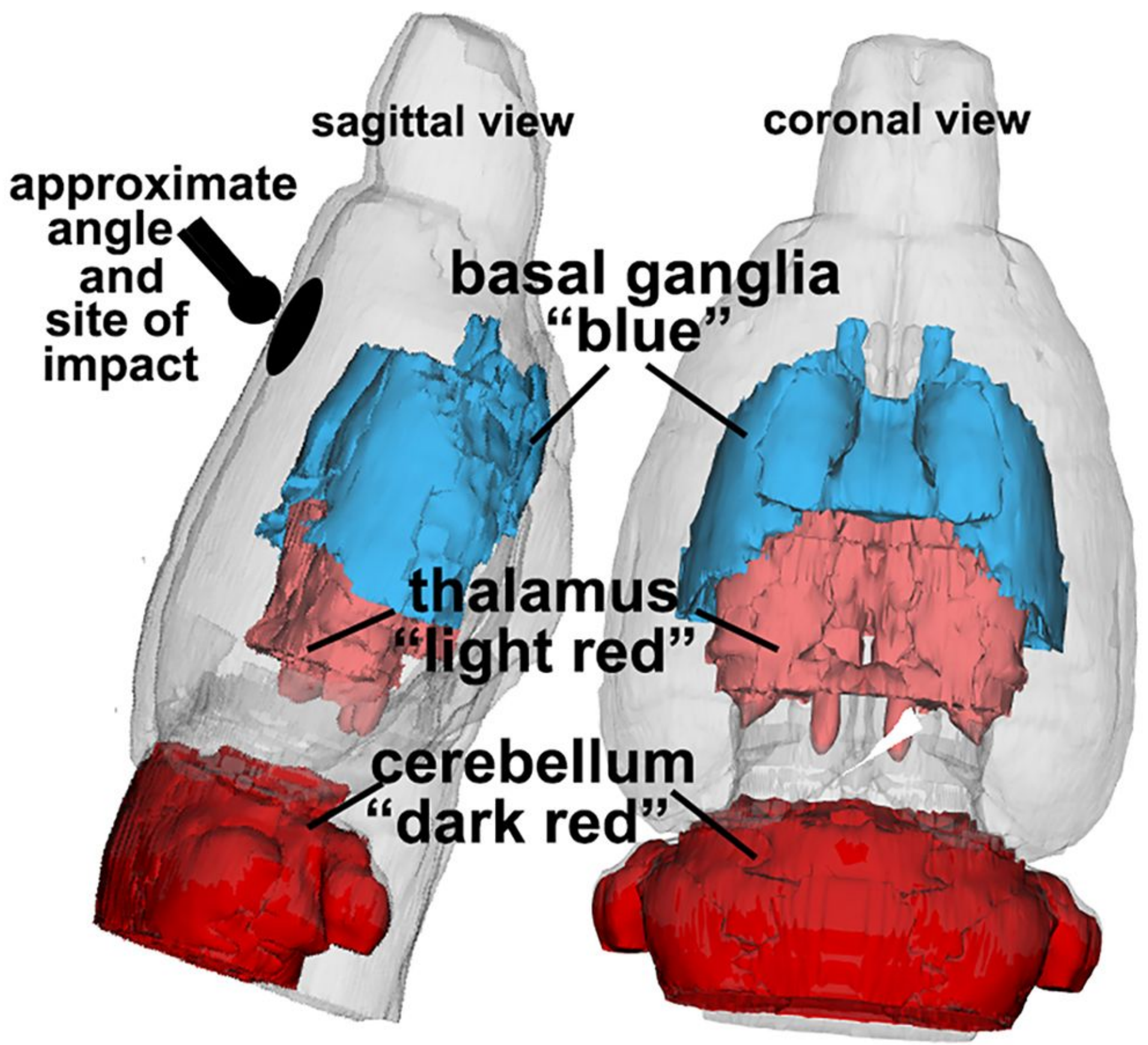


Figure 1

3D reconstruction of affected brain areas Shown is a color-coded reconstruction of brain areas showing significant increases in edema following a single mild hit to the forehead (black ball and circle)

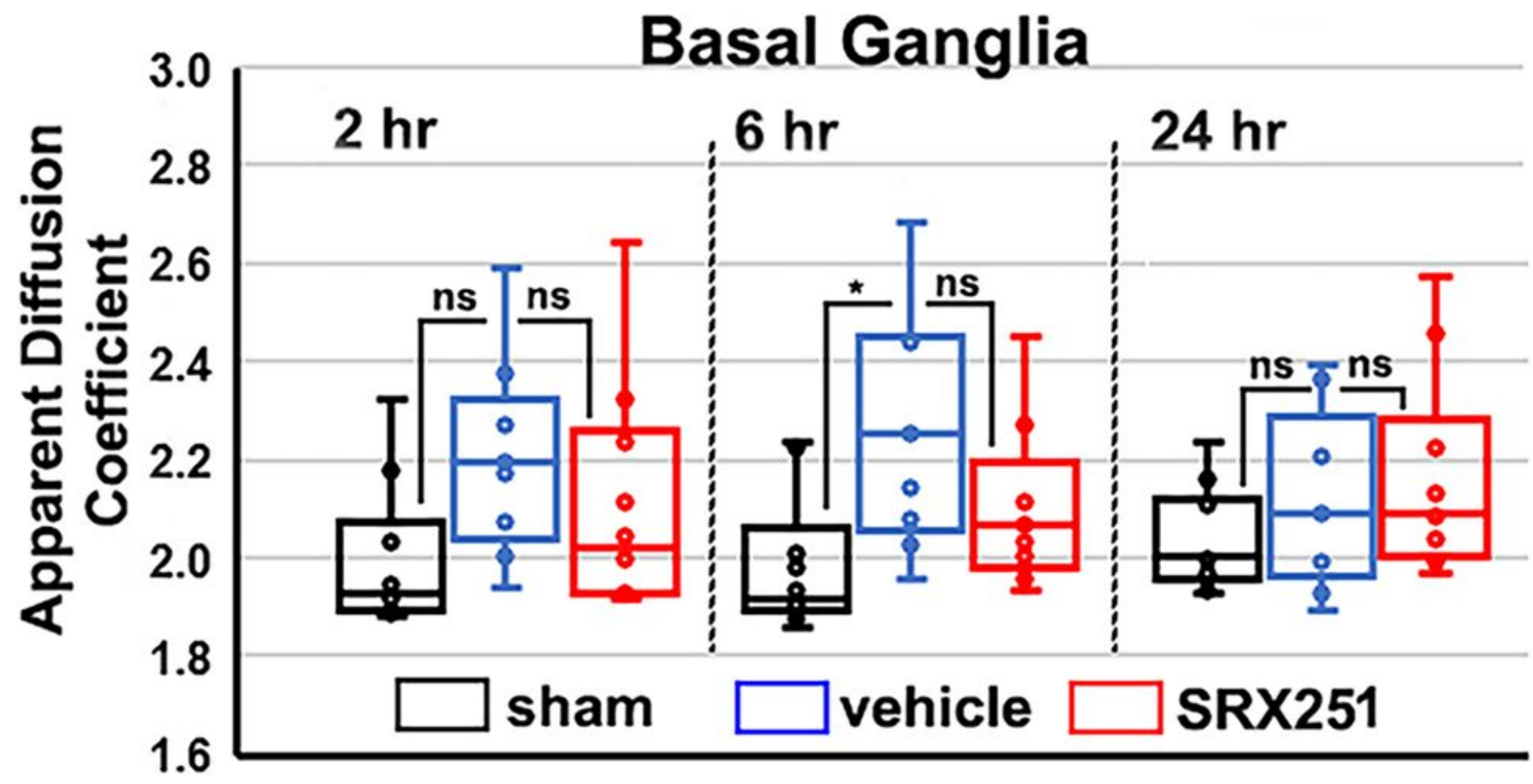

\begin{tabular}{|ccccccc|}
\hline ANOVA & $S S$ & $d f$ & $M S$ & $F$ & $P$-value & $F$ crit \\
\cline { 2 - 7 } Treatment & 1.9709 & 2 & 0.9854 & 6.8764 & 0.0017 & 3.1093 \\
Time & 0.0175 & 2 & 0.0087 & 0.061 & 0.9409 & 3.1093 \\
Interaction & 0.1788 & 4 & 0.0447 & 0.312 & 0.8692 & 2.4844 \\
Within & 11.608 & 81 & 0.1433 & & & \\
Total & 13.775 & 89 & & & & \\
\hline
\end{tabular}

\section{Areas of Basal Ganglia}

accumbens core accumbens shell globus pallidus dorsal medial striatum ventral lateral striatum dorsal lateral striatum

ventral medial striatum

ventral pallidum lateral septal nucleus medial septum

Figure 2 


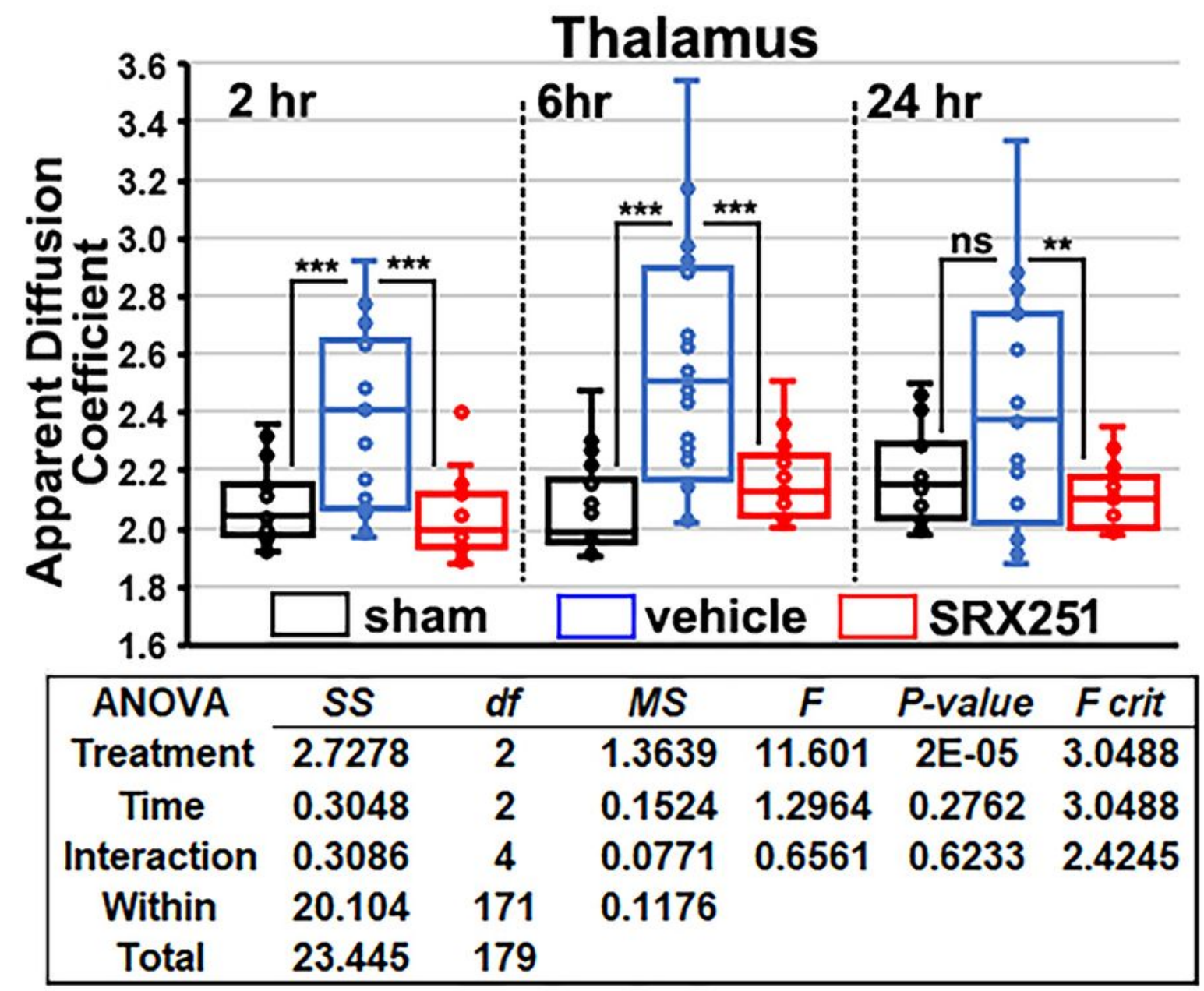

Thalamic Areas

lateral dorsal thalamus

zona incerta

ventral posteriolateral thalamus

ventral posteriolmedial thalamus

ventromedial thalamus

ventrolateral thalamus

ventral anterior thalamus

subthalamic $n$.

reticular $\mathrm{n}$.

reuniens $n$. posterior thalamus

medial pretectal $\mathbf{n}$. anterior pretectal $\mathbf{n}$. parafascicular thalamus medial dorsal thalamus lateral posterior thalamus medial geniculate lateral geniculate anterior thalamus habenula

Figure 3

Edema in thalamus Shown are scatter plots of average ADC values taken from thalamus (20 areas shown below) for sham (black), vehicle (blue) and SRX251 (red) treatments 2, 6 and 24 hrs post head 


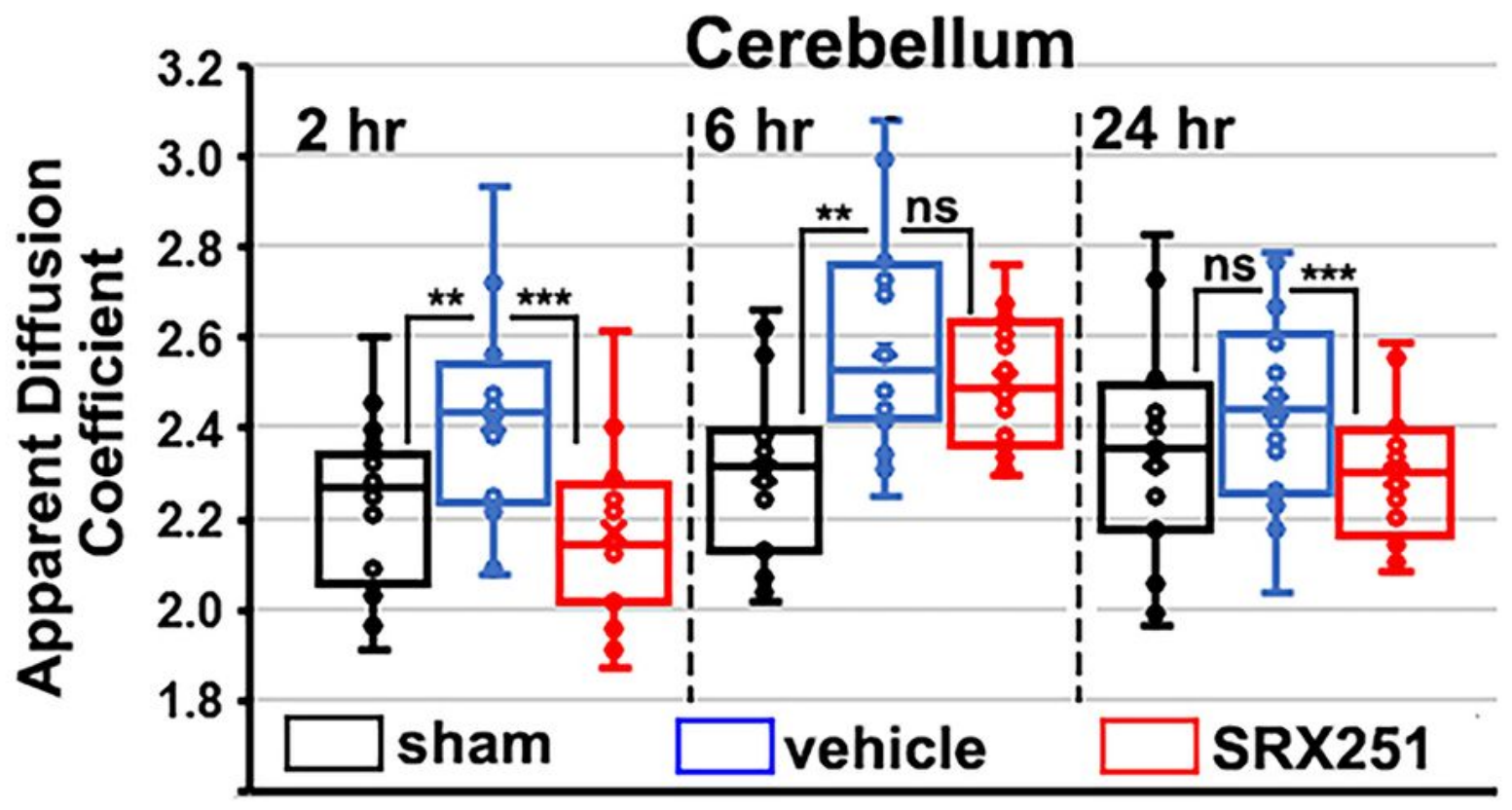

\begin{tabular}{|ccccccc|}
\hline ANOVA & $S S$ & $d f$ & $M S$ & $F$ & $P$-value & $F$ crit \\
\cline { 2 - 7 } Treatment & 1.1476 & 2 & 0.5738 & 13.949 & 2E-06 & 3.0488 \\
Time & 1.3773 & 2 & 0.6887 & 16.741 & $2 \mathrm{E}-07$ & 3.0488 \\
Interaction & 0.4556 & 4 & 0.1139 & 2.7687 & 0.029 & 2.4245 \\
Within & 7.0344 & 171 & 0.0411 & & & \\
Total & 10.015 & 179 & & & & \\
\hline
\end{tabular}

\section{Cerebellar Areas}

1st cerebellar lobule simple lobule cerebellum

2nd cerebellar lobule paramedian lobule

3 rd cerebellar lobule paraflocculus cerebellum 4th cerebellar lobule flocculus cerebellum 5 th cerebellar lobule copula of the pyramis 6th cerebellar lobule crus 1 of ansiform lobule 7 th cerebellar lobule crus 2 of ansiform lobule 8th cerebellar lobule 9th cerebellar lobule medial cerebellar nucleus fastigial lateral cerebellar nucleus 10 th cerebellar lobule interposed nucleus

Figure 4

Edema in cerebellum Shown are scatter plots of average ADC values taken from the cerebellum (20 areas shown below) for sham (black), vehicle (blue) and SRX251 (red) treatments 2, 6 and 24 hrs post head injury. ns - not significant, $* \star \star ~ p<0.001, * \star p<0.01$ 


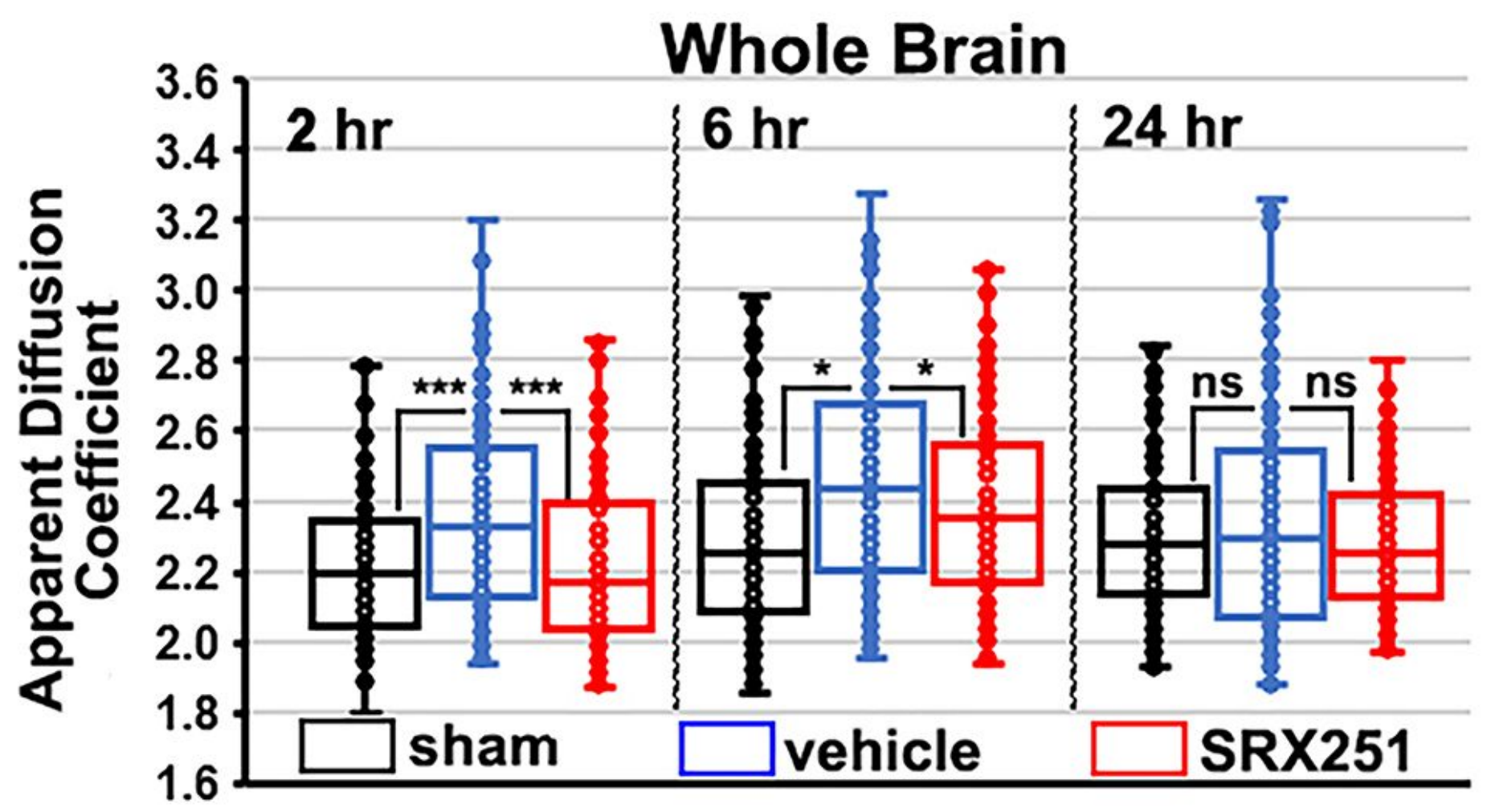

\begin{tabular}{|ccccccc|}
\hline ANOVA & $S S$ & $d f$ & $M S$ & $F$ & $P$-value & $F$ crit \\
\cline { 2 - 7 } Treatment & 4.5783 & 2 & 2.2892 & 23.336 & $1 \mathrm{E}-10$ & 3.0024 \\
Time & 2.2818 & 2 & 1.1409 & 11.631 & $1 \mathrm{E}-05$ & 3.0024 \\
Interaction & 1.2354 & 4 & 0.3088 & 3.1483 & 0.0137 & 2.3786 \\
Within & 131.55 & 1341 & 0.0981 & & & \\
Total & 139.64 & 1349 & & & & \\
\hline
\end{tabular}

Figure 5

Edema in whole brain Shown are scatter plots of average ADC values taken from whole brain (150 areas) for sham (black), vehicle (blue) and SRX251 (red) treatments 2, 6 and 24 hrs post head injury. The analysis from a two-way ANOVA is shown below. ns - not significant, $* \star \star p<0.001, * p<0.05$

\section{Supplementary Files}

This is a list of supplementary files associated with this preprint. Click to download.

- SupplementaryFig1.jpg

- MasterSheetofallAreasinRegions.xlsx 